\title{
ASPECTOS ÉTICOS DA SOCIEDADE DA INFORMAÇÃO: A MARCA DA UNESCO NO DEBATE GLOBAL ${ }^{1}$
}

\author{
English Title: ETHICAL ASPECTS OF THE INFORMATION SOCIETY: THE \\ UNESCO BRAND IN THE GLOBAL DEBATE
}

doi 10.33726/akdpapers2447-7656v12a72021p17-25

Werthein, Jorge $\mathbf{R}^{2}$

RESUMO: Este texto trata de apresentar o O Observatório da Sociedade da Informação - OSI -, ferramenta educativa-comunicacional desenvolvida pela UNESCO. Neste sentido, o objetivo central, reside em conectar as possibilidades oferecidas pelas novas tecnologias de comunicação e a devida construção das identidades socioculturais. Como resultados intermediários, destacamos o fato de que o OSI ainda precisa de aprimoramentos, e que o seu uso, em breve, será indispensável. A fundamentação técnica da proposta repousa em referencial bibliográfico de produção própria e com coautores. $A$ metodologia aplicada foi a de investigação e de revisão de literatura em repositórios físicos e digitais.

PALAVRAS-CHAVE: Tecnologias da Comunicação, UNESCO, OSI

ABSTRACT: This text presents the Information Society Observatory - OSI -, an educational-communication tool developed by UNESCO. In this sense, the main objective lies in connecting the possibilities offered by new communication technologies and the proper construction of sociocultural identities. As intermediate results, we highlight the fact that OSI still needs improvement, and that its use will soon be indispensable. The technical foundation of the proposal rests on a bibliographic reference of its own production and with co-authors. The methodology applied was research and literature review in physical and digital repositories.

KEYWORDS: Communication Technologies, UNESCO, OSI

\footnotetext{
${ }^{1}$ Texto publicado originalmente pela UNESCO, em 2003 (ver WERTHEIN, 2003).

2. Em 2003, este autor atuava como Representante da UNESCO no Brasil. Atualmente, Jorge Ricardo Werthein (com Doutorado em Educação pela Universidade de Stanford), é vice-presidente - SANGARI DO BRASIL e Presidente da SANGARI na Argentina. Tem experiência na área de Educação e Comunicação, (texto adaptado do site escavador.com: https://www.escavador.com/sobre/392823/jorgericardo-werthein).
} 


\section{AKEDIA}

\section{INTRODUÇÃO}

O livre trânsito de informação e conhecimento é um dos componentes que permitem tornar efetivo o mandato da UNESCO (A Organização das Nações Unidas para a Educação, a Ciência e a Cultura) de contribuir para a paz no mundo, por meio da colaboração entre as nações.

A UNESCO incentiva as inúmeras aplicações das novas tecnologias de informação e comunicação, apoiando sistematicamente as políticas públicas voltadas para essa área, ao mesmo tempo em que estimula uma posição crítica e construtiva com relação à contribuição dessas novas tecnologias para o desenvolvimento.

Para a UNESCO, a euforia provocada pela alvorada da Sociedade da Informação não deve impedir o reconhecimento de que a direção e o ritmo da mudança têm sido objeto de preocupação, tanto entre aqueles sobre quem recaem os resultados mais imediatos dessa mudança quanto entre os estudiosos desse novo fenômeno.

Apesar do entusiasmo com esses avanços, não são poucos os setores da sociedade que observam com atenção a evolução histórica do novo paradigma da informação e tornam explícitas, em cada etapa desse desenvolvimento, suas preocupações com as implicações sociais das novas tecnologias.

Não se podem ignorar os desafios éticos que a atual onda de desenvolvimento tecnológico suscita, e a UNESCO entende como parte de seu mandato, garantir que essas preocupações não sejam excluídas do debate. Os desafios da sociedade da informação são inúmeros. Há desafios de caráter técnico e de natureza econômica, assim como desafios culturais, legais e os de natureza psicológica e filosófica. 


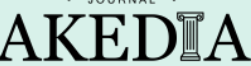

Alguns observadores chegam a formular os desafios éticos da sociedade da informação como uma busca por formas de enfrentar uma múltipla perda: perda de qualificação associada à automação e ao desemprego; de comunicação interpessoal e grupal, transformada pelas novas tecnologias ou mesmo destruída por elas; de privacidade, pela invasão de nosso espaço individual e efeitos da violência visual e poluição acústica; de controle sobre a vida pessoal e o mundo circundante; e do sentido da identidade, associado à profunda intimidação pela crescente complexidade tecnológica.

Já, outros, se dedicam a examinar estratégias de resistência para, como um novo "luddismo" (ou Ludismo [do ingl., ludism, foi um movimento que, contrário à industrialização e à mecanização do trabalho, teve sua origem na Inglaterra, no início do século XIX, e acreditava ser a tecnologia a razão do desemprego e da miséria).

Assim, sob esse ponto de vista, parece lógico lutar contra os aspectos perniciosos da tecnologia virtual, acusada de disseminar na sociedade a utilização de um simulacro de relacionamento como substituto de interações face a face, e contra a alegada usurpação pelo capital do direito de definir a espécie de automação desejada, escolha que tem conduzido a um processo que desqualifica trabalhadores, amplia o controle gerencial sobre o trabalho, intensifica as atividades e corrói a solidariedade.

Algumas das preocupações acima têm sido transformadas com o avanço do novo paradigma, incluindo as ações dos movimentos sociais em reação às implicações consideradas socialmente inaceitáveis. Uma dessas implicações se refere ao desemprego provocado pelo avanço tecnológico. 


\section{DISCUSSÕES}

O chamado desemprego tecnológico e a desqualificação do trabalho, por exemplo, tendem a serem compensados pela reestruturação sistêmica do emprego e re-qualificação dos trabalhadores, mas, nem sempre, essas compensações ocorrem com a velocidade necessária.

Em alguns outros casos, como a perda da privacidade, a sociedade tem-se mobilizado para promover o "comportamento normal responsável" inclusive por meio de legislação adequada para proteger os direitos do cidadão na era digital. A perda do sentimento de controle sobre a própria vida e a perda da identidade são temas que continuam preocupantes e que estão ainda por merecer estratégias eficientes de intervenção (WERTHEIN, 2002).

Talvez a questão ética central do novo paradigma seja a que diz respeito ao aprofundamento de desigualdades sociais, desta vez, sobre o eixo do acesso à informação. O ritmo do avanço tecnológico no alvorecer do novo paradigma tem sido, sob qualquer ótica, extraordinário. O ritmo de expansão da Internet no mundo levou apenas um terço do tempo que precisou o rádio para atingir uma audiência de 50 milhões de pessoas (WERTHEIN, 1979).

A redução dos preços dos computadores por volume de capacidade de processamento facilitou grandemente essa difusão, mas outros fatores além dessa redução de preços continuam a agir, impedindo a superação da relação entre nível de renda e acesso às novas tecnologias. Abrangendo uma população algumas vezes maior que a dos países desenvolvidos, os baixos níveis de renda per capita nos países em desenvolvimento refletem-se em alta taxa de analfabetismo 


\section{AKED艼}

jovem e adulto, baixo acesso à educação formal avançada e à tecnologia da informação tanto convencional quanto moderna (WERTHEIN et al, 1985).

Nesse contexto, o papel das tecnologias de informação na construção de uma "sociedade do conhecimento" inovadora poderá ser muito relevante e contribuir para o desenvolvimento sustentado, mas será acompanhado de muitos riscos. Nesses países, em especial os de nível médio de renda, as novas tecnologias e seu uso requerem investimentos na elevação das capacidades tecnológicas locais e no desenvolvimento das instituições políticas, culturais, econômicas e sociais.

O avanço do novo paradigma dependerá de como serão resolvidas as tensões entre as culturas e modos de organização social existentes e aquelas que começam a se tornar dominantes. As sociedades desses países terão de adaptar suas estruturas institucionais para tratar questões importantes como a proteção da propriedade intelectual. Terão também de examinar a conveniência de estabelecer um equilíbrio entre suas metas de exportação de produtos e serviços de maior conteúdo tecnológico e a criação de oportunidades para ampliar a adoção local das novas tecnologias (WERTHEIN, 2002).

Para muitos analistas, não se pode esperar que estratégias que objetivem acelerar a difusão do novo paradigma erradiquem a pobreza, em curto prazo, e há riscos de que as novas políticas e investimentos nas aplicações das tecnologias de informação introduzam novas forças de exclusão. Tais riscos decorrem de decisões sobre investimentos em alta tecnologia em situação de escassez de recursos, beneficiando camadas mais favorecidas e agudizando desequilíbrios sociais, o que favorece a emergência de uma nova dimensão de desigualdade, o chamado "hiato digital". 
$\mathrm{Na}$ sociedade globalizada em que avança o novo paradigma, novas forças de exclusão emergem tanto em nível local quanto global e requerem esforços em ambos os níveis no sentido de superá-las. Ações fundamentais nessa direção são as que promovem o acesso universal tanto à infraestrutura quanto aos serviços de informação a preços accessíveis.

A conexão internacional dos países em desenvolvimento está extremamente concentrada em poucos pontos de acesso. Novas parcerias e políticas de cooperação internacional deverão ser elaboradas para estimular o desenvolvimento e fortalecimento de redes intraregionais. A instalação de backbones (ao pé da letra, significa "espinha dorsal e, nesta acepção, interliga uma série de servidores que estão distantes, tal como o referido órgão do corpo, conectando diversas partes que não estão próximas) regionais de alta capacidade, por exemplo, permitiria ligar cada país a uma rede global de múltipla conexão em que ninguém dominaria a conectividade.

O acesso universal ao conteúdo e a fontes de conhecimento aponta para a necessidade de resolver vários outros desafios. Um dos mais relevantes é o reconhecimento dos direitos de propriedade intelectual. Do ponto de vista dos países em desenvolvimento, uma delicada negociação deveria assegurar que as novas tecnologias não serão elas mesmas utilizadas para impedir o "uso justo" dos recursos disponíveis na Internet.

A essa negociação dever-se-iam acrescentar ações visando difundir de forma eficiente o princípio de respeito aos direitos de propriedade intelectual, inclusive na Internet. Outra questão é a de elevar o volume de informação de qualidade e de domínio público disponível na Internet no(s) idioma(s) de expressão da população de cada sociedade. Isso envolverá convencer o governo e centros produtores de 
conhecimento financiados por recursos públicos a tornar disponíveis ao público as informações produzidas.

No campo educacional dos países em desenvolvimento, decisões sobre investimentos para a incorporação da informática e da telemática implicam também riscos e desafios. Será essencial identificar o papel que essas novas tecnologias podem desempenhar no processo de desenvolvimento educacional e resolver como utilizá-las de forma a facilitar uma efetiva aceleração do processo em direção a educação para todos, ao longo da vida, com qualidade e garantia de diversidade. As novas tecnologias de informação e comunicação tornam-se, hoje, parte de um vasto instrumental historicamente mobilizado para a educação e aprendizagem. Cabe a cada sociedade decidir que composição do conjunto de tecnologias educacionais mobilizar para atingir suas metas de desenvolvimento.

\section{CONSIDERAÇÕES FINAIS}

Esses são alguns dos desafios que nem sempre são levados em consideração na euforia que acompanha o desenvolvimento da Sociedade da Informação. É para acompanhar esse desenvolvimento e estimular a reflexão crítica sobre eles que a UNESCO mantém um portal, o "UNESCO Observatory of the Information Society", por meio do qual dissemina informação nos idiomas inglês e francês.

Em conformidade com seu compromisso de promover a diversidade cultural e linguística na Internet, a UNESCO fomenta a elaboração de versões do Observatory em vários idiomas, estando já em operação versões em russo e para os países asiáticos.

À Representação da UNESCO no Brasil foi solicitada a tarefa de elaborar, hospedar e manter a versão do Observatório para países de 


\section{AKEDIA}

língua portuguesa. O Observatório da Sociedade da Informação - OSI é um sítio "web" dinâmico, desenvolvido com tecnologia de fonte aberta.

Sua elaboração representou uma oportunidade de trabalho integrado na Representação da UNESCO no Brasil, envolvendo a Coordenação de Comunicação e Informação, a Gerência de Informática, o Centro de Documentação e o setor de Planejamento Visual. O processo de desenvolvimento do OSI foi realizado no período de março a julho de 2003 e envolveu a participação direta de seis profissionais, sendo que para cinco deles essa atividade foi realizada junto com os demais compromissos na Representação.

A versão-teste do OSI foi submetida à análise de um grupo de profissionais atuantes em várias áreas do conhecimento convidados a enviar comentários e sugestões à equipe responsável pelo desenvolvimento. Agradecemos aos seguintes profissionais por seus comentários e sugestões: Adauto Soares, Andrew Radolf, David Moisés, Elza Maria Ferraz Barbosa, Helenise Ribeiro Caldeira Brant, Helio Kuramoto, Jaime Tacher y Samarrel, Lilian Maria Araújo de Rezende, Marlova Noleto, Maximo Migliari, Nelson Simões, Oscar Maeso Varela, Paula Costa, Paulo Henrique Lima, Ricardo Medeiros Coelho e Souza, Thereza Lobo.

É desnecessário dizer que nenhum deles tem responsabilidade pelas imperfeições que ainda persistirem no OSI. A equipe de desenvolvimento na Representação da UNESCO em Brasília continuará envidando todos os esforços no aperfeiçoamento do OSI com a finalidade de oferecer sempre a melhor, mais completa e representativa informação sobre as ações voltadas para a Sociedade da Informação nos países de Língua Portuguesa. 


\section{REFERÊNCIAS}

WERTHEIN, J. R. (Org.). Meios de Comunicação: realidade e Mito. 1. ed. São Paulo: Companhia Editora Nacional, 1979. v. 1.

WERTHEIN, J. R.; CASTILLO, A.; LATAPI, P.; Kaplun. M (Orgs.). Educación de Adultos en América Latina. Buenos Aires: 1985. v. 1.

WERTHEIN, J. R. \& Argumedo M. Educación y Participación. Brasília - DF: Grafica e Editora FCA, 1986. v. 1.

WERTHEIN, J. R. Construção e Identidade - As ideias da UNESCO no Brasil. Brasília - DF: UNESCO Brasil, 2002. v. 1.

WERTHEIN, J. R. Crenças e Esperanças - Os avanços e Desafios da UNESCO no Brasil. Brasília - DF: UNESCO Brasil, 2003. v. 1.

WERTHEIN, Jorge Ricardo. Aspectos Éticos da Sociedade da Informação: a marca da UNESCO no debate global. Artigo publicado, em 03 de setembro de 2003, no Observatório da Sociedade da Informação, de responsabilidade do Setor de Comunicação e Informação da UNESCO no Brasil. Disponível em: http://www.dominiopublico.gov.br/download/texto/ue000248.pdf. Acesso em: 05/07/2021, às $17 \mathrm{~h} 18 \mathrm{~min}$. 